\title{
The posterior superior iliac spine and sacral laminar slope: key anatomical landmarks for freehand S2-alar-iliac screw placement
}

\author{
James D. Lin, MD, MS, ${ }^{1}$ Lee A. Tan, MD, ${ }^{2}$ Chao Wei, MD, ${ }^{3}$ Jamal N. Shillingford, MD, ${ }^{1}$ \\ Joseph L. Laratta, MD, ${ }^{1}$ Joseph M. Lombardi, MD, ${ }^{1}$ Yongjung J. Kim, MD, ${ }^{1}$ \\ Ronald A. Lehman Jr., MD, ${ }^{1}$ and Lawrence G. Lenke, MD1
}

'Department of Orthopedic Surgery, Columbia University Medical Center, The Spine Hospital at NewYork-Presbyterian/ Allen, New York, New York; '2Department of Neurological Surgery, University of California San Francisco Medical Center, San Francisco, California; and 'Department of Spine Surgery, The First Affiliated Hospital of Fujian Medical University, Fuzhou, Fujian, People's Republic of China

OBJECTIVE The S2-alar-iliac (S2AI) screw is an increasingly popular method for spinopelvic fixation. The technique of freehand S2AI screw placement has been recently described. The purpose of this study was to demonstrate, through a CT imaging study of patients with spinal deformity, that screw trajectories based on the posterior superior iliac spine (PSIS) and sacral laminar slope result in reliable freehand S2Al trajectories that traverse safely above the sciatic notch.

METHODS Fifty consecutive patients (age $\geq 18$ years) who underwent primary spinal deformity surgery were included in the study. Simulated S2AI screw trajectories were analyzed with 3D visualization software. The cephalocaudal coordinate for the starting point was $15 \mathrm{~mm}$ cephalad to the PSIS. The mediolateral coordinate for the starting point was in line with the lateral border of the dorsal foramina. The cephalocaudal screw trajectory was perpendicular to the sacral laminar slope. Screw trajectories, lengths, and distance above the sciatic notch were measured.

RESULTS The mean sagittal screw angle (cephalocaudal angulation) was $44.0^{\circ} \pm 8.4^{\circ}$ and the mean transverse angle (mediolateral angulation) was $37.3^{\circ} \pm 4.3^{\circ}$. The mean starting point was $5.9 \pm 5.8 \mathrm{~mm}$ distal to the caudal border of the $\mathrm{S} 1$ foramen. The mean screw length was $99.9 \pm 18.6 \mathrm{~mm}$. Screw trajectories were on average $8.5 \pm 4.3 \mathrm{~mm}$ above the sciatic notch. A total of 97 of 100 screws were placed above the sciatic notch. In patients with transitional lumbosacral anatomy, the starting point on the lumbarized/sacralized side was $3.4 \mathrm{~mm}$ higher than on the contralateral unaffected side.

CONCLUSIONS The PSIS and sacral laminar slope are two important anatomical landmarks for freehand S2AI screw placement.

https://thejns.org/doi/abs/10.3171/2018.3.SPINE171374

KEYWORDS S2Al; freehand; S2-alar-iliac; pelvis; sacropelvic fixation; sacral

$\mathrm{T}$ HE S2-alar-iliac (S2AI) screw for spinopelvic fixation has enjoyed a tremendous increase in popularity over the past decade. S2AI screws provide stable pelvic fixation with screw heads that are in line with S1 screws, with much less prominence, and require much less tissue dissection compared to traditional pelvic screws. ${ }^{4}$ Multiple techniques have been described to optimize screw placement, including fluoroscopic guidance, robotic assistance, surgical navigation, and manual palpation of the greater trochanter. $6,7,11,13$ The senior author prefers to place S2AI screws using the freehand technique guided by local anatomical landmarks only, without intraoperative fluoroscopy. This method improves intraoperative efficiency by allowing a seamless transition from freehand pelvic instrumentation to freehand thoracolumbar screw placement, which decreases radiation exposure and decreases surgeon fatigue by obviating the need to wear lead protective gear.

There have been few published studies regarding free-

ABBREVIATIONS ICC = intraclass correlation coefficient; $\mathrm{PSIS}=$ posterior superior iliac spine; $\mathrm{SI}=$ sacroiliac; $\mathrm{S} 2 \mathrm{AI}=\mathrm{S} 2$-alar-iliac .

SUBMITTED December 27, 2017. ACCEPTED March 14, 2018.

INCLUDE WHEN CITING Published online July 27, 2018; DOI: 10.3171/2018.3.SPINE171374. 


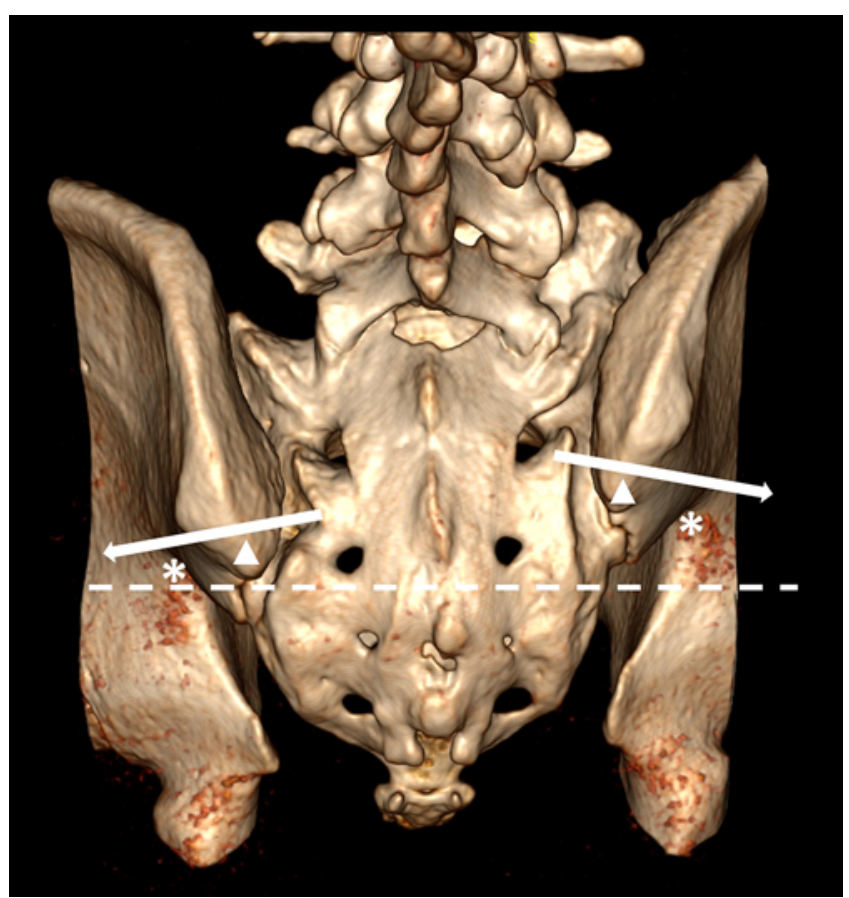

FIG. 1. Posterior view of right-sided Castellvi type Illa lumbosacral junction, associated with L5 contribution to the SI joint and elevation of right hemipelvis. Dotted line highlights asymmetrical position of sciatic notches $\left(^{*}\right)$ bilaterally. Triangles indicate the most caudal aspect of the PSIS. White arrows show approximate starting point, $15 \mathrm{~mm}$ cephalad to the caudal PSIS, and trajectory of the S2AI screws. Figure is available in color online only.

hand placement of S2AI screws. We recently published our series of patients treated with freehand S2AI screws along with a description of the technique, demonstrating safe and reliable placement of 100 consecutive S2AI screws with no neurovascular complications. ${ }^{16}$

However, freehand placement of S2AI screws can be challenging, especially in the setting of transitional lumbosacral anatomy, where unilateral lumbarization/sacralization of the transitional vertebra introduces asymmetry in the dorsal sacral landmarks and occasionally elevates the hemipelvis (Fig. 1). In this special setting, using the "one size fits all" starting point caudal to the S1 dorsal foramen can result in unreliable screw trajectories, especially when placing the screws without fluoroscopy. ${ }^{8}$

There are two important local anatomical landmarks that are critical to reliable placement of freehand S2AI screws: 1) the posterior superior iliac spine (PSIS), and 2) the sacral laminar slope. The PSIS is used to determine the cephalocaudal location of the starting point along the lateral border of the dorsal sacral foramina. A line perpendicular to the sacral laminar slope determines the sagittal screw trajectory. Used in combination, the PSIS and sacral laminar slope provide anatomical landmarks on both the ilium and the sacrum, which allow a safe screw trajectory above the sciatic notch, while adjusting for variability in the sagittal screw angle in relation to pelvic tilt (Fig. 2).

The purpose of this study was to demonstrate, using preoperative $\mathrm{CT}$ imaging studies of patients with spinal

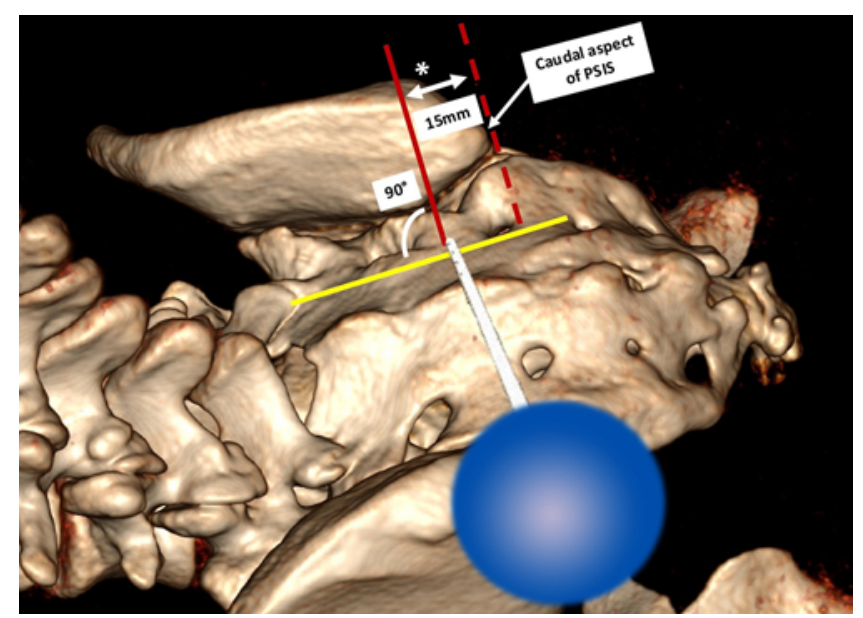

FIG. 2. 3D model demonstrating intraoperative view when attempting to place a left-sided S2AI screw. The PSIS is marked with an asterisk. The cephalocaudal starting point is $15 \mathrm{~mm}$ cephalad (red line) to the caudal aspect of the PSIS (dotted red line), which is typically between the S1 and S2 dorsal foramen as shown here. The sagittal angulation is perpendicular to the slope of the sacral lamina (yellow line). The mediolateral angulation is not illustrated here but is approximately $40^{\circ}$ and adjusted based on tactile feedback obtained using the blunt pedicle probe. Figure is available in color online only.

deformity, that screw trajectories based on the PSIS and sacral laminar slope result in reliable freehand S2AI trajectories that traverse safely above the sciatic notch.

\section{Methods}

The research protocol was approved by our institutional review board. Consecutive adult patients (age $\geq 18$ years) who underwent primary spinal deformity surgery performed at a single institution by the senior author (L.G.L.) were identified. Patients were excluded if the preoperative CT scan was not available, or if the CT scan did not show enough of the pelvis and sciatic notch to evaluate S2AI screw placement.

\section{Simulated Screw Placement}

Simulated S2AI screws were placed using preoperative CT scans by manipulating the gantry in three axes with 3D visualization software (VitreaCore version 6.7.6; ViTAL). Measurements were performed by two independent observers. Images were viewed simultaneously in axial, sagittal, and coronal planes. The gantry was adjusted to orient the sacrum in the coronal and axial planes to adjust for pelvic obliquity and truncal rotation, respectively (Fig. 3A).

The cephalocaudal starting point was chosen by identifying a point $15 \mathrm{~mm}$ cephalad to the caudal aspect of the PSIS. The mediolateral starting point was chosen to be in line with the lateral aspect of the $\mathrm{S} 1$ foramen. The sagittal trajectory of the S2AI screw was determined by measuring a perpendicular line to the sacral laminar slope at the level of the starting point. The axial plane trajectory (transverse angle) of the screw was chosen as the line most closely bisecting the ileum (Fig. 3). 


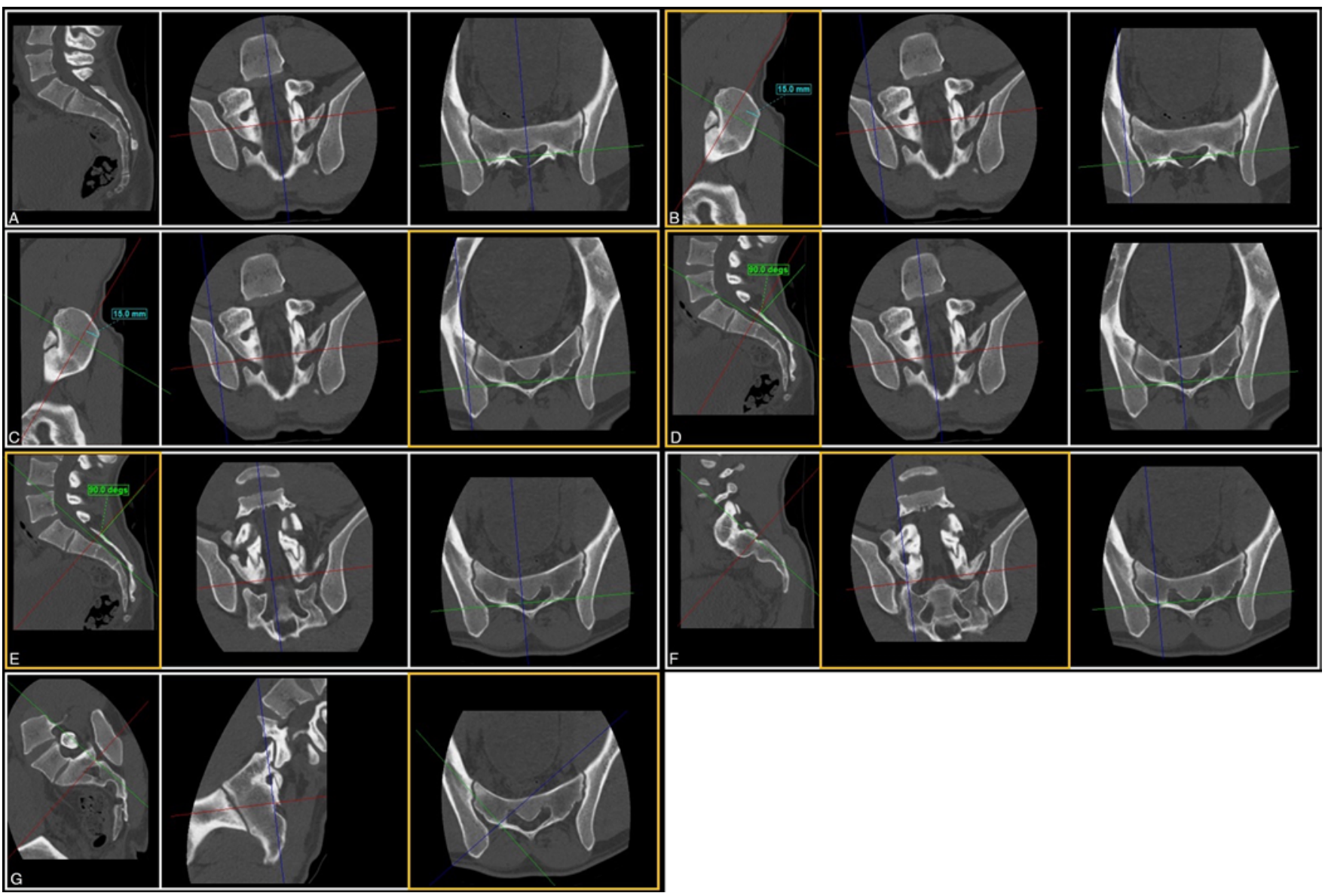

FIG. 3. Sagittal, coronal, and axial views showing measurement methodology for the patient with Castellvi type Illa transitional anatomy shown in Fig. 1. Boxes in yellow highlight areas of interest. A: Axes of visualization software adjusted to be orthogonal to the sacrum on sagittal, coronal, and axial views. B: The sagittal image is centered over the tip of the PSIS and a point $15 \mathrm{~mm}$ proximal to the distal aspect of the PSIS is measured. C: The cephalocaudal position is adjusted to $15 \mathrm{~mm}$ proximal to the distal aspect of the PSIS, representing the final cephalocaudal position of the starting point. D: A line perpendicular to the sacral laminar slope is created using the angle measuring tool. E: The sagittal trajectory is adjusted to this perpendicular line, representing the final sagittal screw angle. F: The mediolateral position is adjusted to the lateral aspect of the sacral foramina to determine the final mediolateral position of the starting point. G: The axial screw trajectory is set to bisect the ilium, resulting in an S2Al screw trajectory above the sciatic notch. Figure is available in color online only.

Screw length, sagittal and transverse angles, distance to the sacroiliac (SI) joint, distance above the sciatic notch, and location of the starting point relative to the caudal aspect of the S1 foramen were recorded. Screws were judged to be below the sciatic notch if either one of the two observers' measurements was distal to the notch. This was done because if the screw trajectory was distal to the sciatic notch, sagittal and transverse angles could not be measured and averaged between the two observers.

CT scans were reviewed for transitional lumbosacral anatomy and classified according to the Castellvi classification: type I-dysplastic transverse process greater than $19 \mathrm{~mm}$; type II-incomplete lumbarization/sacralization; type III-complete lumbarization/sacralization; and type IV-mixed.

\section{Statistical Analysis}

Distribution of variables is presented as the mean $\pm \mathrm{SD}$.
The Student t-test was used to determine clinical significance between groups. A p value of $<0.05$ was considered statistically significant. Concordance among raters was assessed with the intraclass correlation coefficient (ICC).

\section{Results}

Fifty consecutive patients who fulfilled the selection criteria were identified. The mean age of the patient group was 50 years, with $74 \%$ of patients being female. Preoperative diagnoses included adult idiopathic scoliosis, degenerative scoliosis, congenital scoliosis and kyphoscoliosis, and kyphosis (Table 1).

A total of 100 simulated S2AI screw trajectories were measured. The mean sagittal screw angle was $44.0^{\circ} \pm 8.4^{\circ}$, and the mean transverse angle was $37.3^{\circ} \pm 4.3^{\circ}$. The mean starting point was $5.9 \pm 5.8 \mathrm{~mm}$ distal to the caudal border of the S1 foramen. The mean screw length was 99.9 $\pm 18.6 \mathrm{~mm}$; the mean distance from the starting point to 
TABLE 1. Patient demographics

\begin{tabular}{ll}
\hline \multicolumn{1}{c}{ Characteristic } & Value \\
\hline No. of patients & 50 \\
\hline Mean age (yrs) & 50.0 \\
\hline$\%$ female & 74 \\
\hline Diagnosis & \\
\hline Adult idiopathic scoliosis & 22 \\
\hline Degenerative scoliosis & 18 \\
\hline Congenital scoliosis & 6 \\
\hline Kyphosis & 4 \\
\hline
\end{tabular}

the SI joint was $32.5 \pm 4.9 \mathrm{~mm}$; and the mean S2AI screw to $\mathrm{S} 2$ angle was $1.5^{\circ} \pm 9.1^{\circ}$ (Table 2 ). When comparing male and female patients, there were no statistically significant differences in sagittal angle $\left(43.0^{\circ}\right.$ vs $44.3^{\circ}, \mathrm{p}=$ $0.52)$, transverse angle $\left(38.5^{\circ}\right.$ vs $\left.36.9^{\circ}, \mathrm{p}=0.11\right)$, or screw length (102.6 mm vs $99.0 \mathrm{~mm}, \mathrm{p}=0.42)$.

Screw trajectories were on average $8.5 \pm 4.3 \mathrm{~mm}$ above the sciatic notch. A total of 97 of 100 simulated screws were placed above the sciatic notch by both observers. There were 3 simulated screw trajectories in which at least one measurement was distal to the notch, with the lowest individual measurement being $5.5 \mathrm{~mm}$ distal to the sciatic notch. The average measurement among these 3 screws was $2.2 \mathrm{~mm}$ above the sciatic notch. The ICCs (right/left) between the two observers were $0.956 / 0.954$ for sagittal screw trajectory, $0.848 / 0.719$ for transverse screw trajectory, $0.639 / 0.753$ for distance above the sciatic notch, and 0.308/0.344 for distance below the S1 foramen.

There were 14 patients with transitional lumbosacral anatomy in the study population: 7 patients had Castellvi type IIa deformity, 1 had type IIb, 5 had type IIIa, and 1 had type IV (Table 3, Fig. 4).

A side-to-side comparison of the starting point position relative to the $\mathrm{S} 1$ dorsal foramen was performed. In patients with transitional lumbosacral anatomy, the starting point on the lumbarized/sacralized side was $3.4 \mathrm{~mm}$ higher than on the contralateral side, presenting a statistically significant difference to the $0.72 \mathrm{~mm}$ side-to-side difference in patients without lumbosacral transitional anatomy $(\mathrm{p}=0.02)$.

\section{Discussion}

The S2AI screw was first described by O'Brien et al. and by Kebaish for spinopelvic fixation in the settings of pediatric and adult spinal deformity correction, respectively. 6,10,11 The screw trajectory starts between the S1 and S2 dorsal foramina, with axial and sagittal plane trajectories of approximately $40^{\circ}$, and crosses the SI joint before traversing the ilium toward the anterior inferior iliac spine. ${ }^{4}$ Compared to traditional iliac screws, S2AI screws are less prominent due to a deeper starting point, ${ }^{4}$ are biomechanically equivalent, ${ }^{12}$ and are in line with the S1 screws, ${ }^{4}$ thereby obviating the need for cross-connectors.

Most descriptions of S2AI screw placement require fluoroscopy or navigation to ensure safe screw placement cephalad to the sciatic notch., ${ }^{1,5,114}$ This is due to the considerable variation in sagittal screw angle from the mean of approximately $40^{\circ}$. We have previously shown that the sagittal screw angle varies with pelvic tilt (Shillingford JN, Laratta JL, Lin JD, et al.: The Role of Pelvic Parameters on S2 Alar-Iliac Screw Trajectory. E-Poster at the Scoliosis Research Society 52nd Annual Meeting 2017, Philadelphia, PA). Moreover, transitional lumbosacral anatomy occurs in up to $30 \%$ of patients, ${ }^{3}$ which can result in asymmetrical dorsal sacral landmarks and occasionally asymmetrical elevation of the hemipelvis (Fig. 1). We believe that safe and reliable freehand placement of S2AI screws depends on two local anatomical landmarks: 1) the PSIS, a bony landmark on the ileum, to ensure screw trajectory above the sciatic notch; and 2) the sacral laminal slope, to account for variation in pelvic orientation and transitional lumbosacral anatomy.

In this CT study, 100 simulated freehand S2AI screw trajectories were analyzed in 50 patients with spinal deformity by using the PSIS and the sacral laminar slope as landmarks. The screw starting point was $15 \mathrm{~mm}$ cephalad to the caudal PSIS in the cephalocaudal direction, and on the lateral border of the dorsal sacral foramina. The 15-mm distance was chosen based on our clinical experience. The sagittal screw trajectory was perpendicular to the sacral laminar slope. Ninety-seven of 100 screws were placed safely above the sciatic notch, with a mean screw length of $99.9 \mathrm{~mm}$, a mean starting point $5.9 \mathrm{~mm}$ below the $\mathrm{S} 1$ dorsal foramen, and a mean of $8.5 \mathrm{~mm}$ above the sciatic notch. In patients with unilateral lumbosacral

TABLE 2. Screw measurements

\begin{tabular}{lcccc}
\hline \multicolumn{1}{c}{ Variable } & $\mathrm{Rt}$ & $\mathrm{Lt}$ & Total & $\mathrm{p} \mathrm{Value} \mathrm{(rt} \mathrm{vs} \mathrm{It)}$ \\
\hline No. of screws & 50 & 50 & 100 & \\
\hline Sagittal angle & $43.7^{\circ} \pm 8.6^{\circ}$ & $44.3^{\circ} \pm 8.2^{\circ}$ & $44.0^{\circ} \pm 8.4^{\circ}$ & 0.744 \\
\hline Transverse angle & $38.3^{\circ} \pm 4.5^{\circ}$ & $36.3^{\circ} \pm 3.8^{\circ}$ & $37.3^{\circ} \pm 4.3^{\circ}$ & $\mathbf{0 . 0 1 6}$ \\
\hline Distance above sciatic notch (mm) & $9.4 \pm 4.5$ & $7.5 \pm 4.0$ & $8.5 \pm 4.3$ & 0.025 \\
\hline Screw length (mm) & $98.4 \pm 20.4$ & $101.5 \pm 16.8$ & $99.9 \pm 18.6$ & 0.410 \\
\hline Distance to SI joint (mm) & $32.5 \pm 5.8$ & $32.5 \pm 3.9$ & $32.5 \pm 4.9$ & 0.972 \\
\hline Starting point (mm below S1 foramen) & $6.5 \pm 6.0$ & $5.3 \pm 5.6$ & $5.9 \pm 5.8$ & 0.308 \\
\hline S2Al to S1 angle & $1.2^{\circ} \pm 9.0^{\circ}$ & $1.8^{\circ} \pm 9.3^{\circ}$ & $1.5^{\circ} \pm 9.1^{\circ}$ & 0.764 \\
\hline
\end{tabular}

Boldface type indicates statistical significance. Measurements are expressed as the mean \pm SD. 
TABLE 3. Distribution of lumbosacral transitional anatomy

\begin{tabular}{cccc}
\hline Castellvi Classification & Lt & Rt & Total \\
\hline la & 0 & 0 & 0 \\
\hline Ila & 5 & 2 & 7 \\
\hline Ilb & $N A$ & $N A$ & 1 \\
\hline Illa & 3 & 2 & 5 \\
\hline IIlb & $N A$ & $N A$ & 0 \\
\hline IV & 1 & 0 & 1 \\
\hline Total & 9 & 4 & 14 \\
\hline
\end{tabular}

$\mathrm{NA}=$ not applicable.

Castellvi classes (see Castellvi et al.): I, dysplastic transverse process; II, incomplete lumbarization/sacralization; III, complete fusion; IV, mixed; a, unilateral; $b$, bilateral. Laterality is designated except in the bilateral subtype. In type IV, the side with more advanced lumbarization/sacralization is designated. The total number of patients is off by 1 , because 1 patient had bilateral deformity.

transitional anatomy, the screw starting point was $3.4 \mathrm{~mm}$ more cephalad on the transitional side.

Chang et al. performed a CT study of ideal S2AI screw trajectories in 20 patients, with a mean screw length of $106 \mathrm{~mm}$, a mean transverse screw angulation of $40^{\circ}$, and a mean sagittal screw angulation of $39^{\circ}$. The screw trajectories traversed $35 \mathrm{~mm}$ of sacral bone before crossing into the ilium. ${ }^{4}$ O'Brien et al. performed a cadaveric study of S2AI screw placement, with a mean screw length of 84 $\mathrm{mm}$, transverse screw angulation averaging $44^{\circ} / 37.9^{\circ}$ (left/ right), and sagittal screw angulation averaging $32^{\circ} / 34.6^{\circ}$ (left/right). ${ }^{11}$ Our measured screw lengths and trajectories are in agreement with these findings. Our results show a statistically significant side-to-side asymmetry in transverse angle $\left(36.3^{\circ}\right.$ vs $38.3^{\circ}$ [left/right]), similar to the results of O'Brien et al. This difference does not appear to be meaningful clinically.

The description of the S2AI screw starting point varies slightly in the published literature, ranging from $1 \mathrm{~mm}$ distal and lateral to the S1 foramen, to the midpoint between S1 and S2.9,11 Our starting point is referenced 15 $\mathrm{mm}$ cephalad to the caudal aspect of the PSIS, which corresponds to an average of $5.9 \mathrm{~mm}$ below the $\mathrm{S} 1$ foramen, consistent with the literature. Notably, our results show that in patients with unilateral lumbarization/sacralization, the starting point is $3.4 \mathrm{~mm}$ cephalad on the sacralized side. This finding can be rationalized from an embryological perspective. The SI joint typically develops from the S1-3 sacral segments. ${ }^{2}$ If a unilateral sacralized L5 (Castellvi IIIa) contributes to the SI joint, resulting in a more cephalad position of the joint, a more cephalad screw starting point is required to traverse it. This is highly important during freehand placement of S2AI screws, because there is no opportunity to adjust the sagittal screw angle to be cephalad to the sciatic notch by using fluoroscopy. This technical nuance has not been previously described.

There have been only a few published studies on freehand S2AI screw placement. We recently published our clinical experience with 100 consecutive freehand S2AI screws analyzed with O-arm imaging. ${ }^{16}$ Only 5 screws were placed with moderate to severe cortical breeches, all of which were posterior and only involved the distal por-
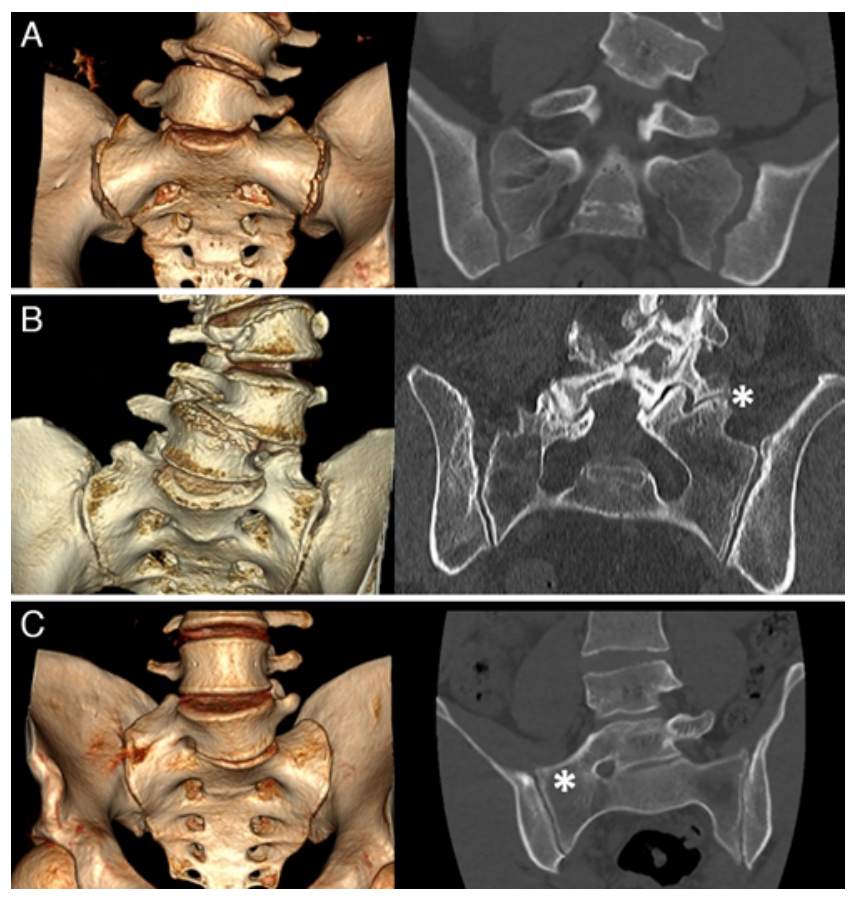

FIG. 4. Examples of lumbosacral junctional variations in the current study cohort. Asterisks denote area of atypical articulation between L5 and sacrum. A: Normal lumbosacral anatomy. B: Castellvi type lla, with pseudarthrosis of left L5 transverse process with sacrum. C: Castellvi type IIla, with complete osseous fusion of right $L 5$ transverse process with sacrum. Figure is available in color online only.

tion of the screw tip. There were no neurovascular complications. ${ }^{16}$ Park and colleagues published their technique and results of freehand S2AI screws in both a cadaveric and clinical study. ${ }^{14,15}$ They reported on 45 consecutive screws placed, with no neurovascular complications and 5 asymptomatic cortical breaches. Of note, they used the midpoint between $\mathrm{S} 1$ and $\mathrm{S} 2$ as their starting point, and directed the gearshift approximately $20^{\circ}$ in the sagittal plane and $30^{\circ}$ in the horizontal plane. They also used a portable lateral radiograph to estimate sagittal screw angle after positioning. ${ }^{14}$ Our present study differs from the aforementioned studies in that this is a pure anatomical study to prove the value of two important dorsal landmarks, the PSIS and the sacral laminar slope, in guiding optimal S2AI screw trajectory.

There are several limitations to this study. This is a CT study based on simulated screw trajectories in a limited number of patients. However, we believe our inclusion of only patients with deformity makes our findings more generalizable to the challenges encountered in spinal deformity surgery, including pelvic obliquity and transitional lumbosacral anatomy. Patients were excluded if they did not have a preoperative CT scan or had incomplete CT scans without visualization of the sciatic notch (which would preclude screw measurements for this study). This may have introduced selection bias into our study group, because most of the patients without preoperative CT scans (10 patients were excluded) were younger patients with idiopathic scoliosis. Fortunately, in our final 
study cohort nearly equal numbers of patients with idiopathic and degenerative scoliosis were represented (Table 1). Whereas the ICC of our screw trajectory parameters ranged from moderate to high $(0.639-0.956)$, the ICC of the screw starting point relative to the caudal aspect of the S1 foramen was low (0.308-0.344). However, the measured distance to the S1 foramen was not used in determining screw trajectories, but only to compare the PSIS-referenced starting point to historical S1/S2 foramen-referenced starting points. The low ICC in this case reflects the difficulty in consistently identifying the caudal aspect of the S1 foramen on coronal imaging, because dorsal foramina are not perfectly cylindrical structures. The number of patients with transitional lumbosacral anatomy (28\%) is similar to that in previous published reports. ${ }^{3} \mathrm{We}$ did not take into account screw diameters in this study, because this was a limitation in our visualization software. However, in our clinical experience, as long as the trajectory is within the confines of the cortex, the curved tip of the probe and the surgeon's tactile feel should guide the screw to the correct path.

\section{Conclusions}

The PSIS and sacral laminar slope are two key anatomical landmarks for safe and reliable placement of freehand S2AI screws. In the absence of fluoroscopy, a point $15 \mathrm{~mm}$ cephalad to the caudal aspect of the PSIS acts as a proxy for the location of the sciatic notch, and the sacral laminar slope helps account for differences in pelvic tilt or orientation. As with freehand pedicle screw placement, freehand S2AI screws should be placed in a stepwise, consistent, and meticulous manner, with careful attention to local anatomical landmarks and intraoperative tactile feedback.

\section{References}

1. Bederman SS, Hahn P, Colin V, Kiester DP, Bhatia NN: Robotic guidance for S2-alar-iliac screws in spinal deformity correction. J Spinal Disord Tech 30:E49-E53, 2017

2. Bellamy N, Park W, Rooney PJ: What do we know about the sacroiliac joint? Semin Arthritis Rheum 12:282-313, 1983

3. Castellvi AE, Goldstein LA, Chan DP: Lumbosacral transitional vertebrae and their relationship with lumbar extradural defects. Spine (Phila Pa 1976) 9:493-495, 1984

4. Chang TL, Sponseller PD, Kebaish KM, Fishman EK: Low profile pelvic fixation: anatomic parameters for sacral alariliac fixation versus traditional iliac fixation. Spine (Phila Pa 1976) 34:436-440, 2009

5. Jain A, Kebaish KM, Sponseller PD: Sacral-alar-iliac fixation in pediatric deformity: radiographic outcomes and complications. Spine Deform 4:225-229, 2016

6. Kebaish KM: Sacropelvic fixation: techniques and complications. Spine (Phila Pa 1976) 35:2245-2251, 2010

7. Laratta JL, Shillingford JN, Lombardi JM, Alrabaa RG, Benkli B, Fischer C, et al: Accuracy of S2 alar-iliac screw placement under robotic guidance. Spine Deform 6:130-136, 2018

8. Lin JD, Tan LA, Shillingford J, Laratta JL, Kim Y, Lehman RA Jr, et al: The sacral laminar slope is an anatomic landmark for freehand S2AI screw insertion. Spine J 17 (10 Suppl):S262, 2017 (Abstract)

9. Mattei TA, Fassett DR: Combined S-1 and S-2 sacral alariliac screws as a salvage technique for pelvic fixation after pseudarthrosis and lumbosacropelvic instability: combined
S-1 and S-2 sacral alar-iliac screws as a salvage technique for pelvic fixation after pseudarthrosis and lumbosacropelvic instability: technical note. J Neurosurg Spine 19:321-330, 2013

10. O’Brien JR, Matteini L, Yu WD, Kebaish KM: Feasibility of minimally invasive sacropelvic fixation: percutaneous S2 alar iliac fixation. Spine (Phila Pa 1976) 35:460-464, 2010

11. O'Brien JR, Yu WD, Bhatnagar R, Sponseller P, Kebaish KM: An anatomic study of the S2 iliac technique for lumbopelvic screw placement. Spine (Phila Pa 1976) 34:E439E442, 2009

12. O’Brien JR, Yu W, Kaufman BE, Bucklen B, Salloum K, Khalil S, et al: Biomechanical evaluation of S2 alar-iliac screws: effect of length and quad-cortical purchase as compared with iliac fixation. Spine (Phila Pa 1976) 38:E1250 E1255, 2013

13. Ohya J, Vogel TD, Dhall SS, Berven S, Mummaneni PV: Technique and nuances of an S-2 alar iliac screw for lumbosacral fixation in patients with transitional and normal anatomy. Neurosurg Focus 41(1):Videosupp13, 2016

14. Park JH, Hyun SJ, Kim KJ, Jahng TA: Free hand insertion technique of S2 sacral alar-iliac screws for spino-pelvic fixation: technical note, acadaveric study. J Korean Neurosurg Soc 58:578-581, 2015

15. Park YS, Hyun SJ, Park JH, Kim KJ, Jahng TA, Kim HJ: Radiographic and clinical results of freehand S2 alar-iliac screw placement for spinopelvic fixation: an analysis of 45 consecutive screws. Clin Spine Surg 30:E877-E882, 2017

16. Shillingford JN, Laratta JL, Tan LA, Sarpong NO, Lin JD, Fischer CR, et al: The free-hand technique for S2-alar-iliac screw placement: a safe and effective method for sacropelvic fixation in adult spinal deformity. J Bone Jt Surg Am 100:334-342, 2018

\section{Disclosures}

Dr. Lenke receives research support from AOSpine, Scoliosis Research Society, EOS, and Setting Scoliosis Straight Foundation. Dr. Lenke is a paid consultant for and/or received royalties from Medtronic, DePuy-Synthes Spine, K2M, and Quality Medical Publishing. He is also on the editorial or governing board of Journal of Neurosurgery: Spine, Spine Deformity Journal, Spine, Scoliosis, Journal of Spinal Disorders \& Techniques, www.iscoliosis. com, www.spineuniverse.com, Backtalk (Scoliosis Assn), Global Spine Outreach, and Orthopaedic Research and Education Foundation. Dr. Lehman is on the editorial or governing board of Spine Deformity, The Spine Journal, AOSpine, Cervical Spine Research Society, North American Spine Society, and Scoliosis Research Society. Dr. Lehman is a paid presenter, consultant, or speaker for DePuy (a Johnson \& Johnson company), Medtronic, and Stryker. He receives publishing royalties from Wolters Kluwer Health-Lippincott Williams \& Wilkins.

\section{Author Contributions}

Conception and design: Lenke, Lin, Tan, Shillingford, Laratta, Lombardi, Kim, Lehman. Acquisition of data: Lin, Tan, Wei. Analysis and interpretation of data: Lin, Laratta. Drafting the article: Lin. Critically revising the article: all authors. Reviewed submitted version of manuscript: all authors. Statistical analysis: Lin, Shillingford. Study supervision: Lenke, Lin.

\section{Correspondence}

Lawrence G. Lenke: Columbia University Medical Center, The Spine Hospital at New York Presbyterian/Allen, New York, NY. 112989@cumc.columbia.edu. 